\title{
Patient-reported measures of quality of life and functional capacity in adhesive capsulitis
}

\author{
Marcos Rassi Fernandes ${ }^{1 *}$ \\ ${ }^{1} \mathrm{MD}$, PhD in Health Science, Department of Orthopedics/Traumatology, Faculty of Medicine, Universidade Federal de Goiás, Goiânia, GO, Brazil
}

\section{SUMMARY}

Study conducted by the Health Science Strictu Sensu Post-Graduated Program, Faculty of Medicine, Universidade Federal de Goiás, Goiânia, GO, Brazil

Article received: $7 / 12 / 2016$ Accepted for publication: 11/7/2016

*Correspondence: Address: Av. Azaléias, Qd. 10, Lt. 20 Aparecida de Goiânia, GO - Brazil Postal code: 74935-187 marcosombro@ig.com.br
Objective: To evaluate patient-reported measures of quality of life and functional capacity in adhesive capsulitis before and after suprascapular nerve block treatment; to analyze the influence of clinical and sociodemographic variables on both the outcome and correlation between the respective instruments.

Method: A prospective clinical study was performed with adhesive capsulitis patients. Inclusion criteria were clinical diagnosis of adhesive capsulitis and a shoulder imaging test. The WHOQOL-BREF and DASH instruments were administered before and after treatment. A Constant test score of 55 points was used as a cutoff point for discontinuation of treatment. Mean values were compared using paired t-test and Wilcoxon. The Pearson or Spearman coefficients were used for correlation analysis. Multiple linear regression analysis was carried out using variables with $\mathrm{p}<0.20$ as predictors in univariate analysis and WHOQOL domains and DASH as outcomes. The significance level was $5 \%$.

Results: Forty-three patients were evaluated. The comparison between WHOQOL-BREF and DASH mean values before and after the blocks, $\mathrm{p}<0.05$. DASH correlated negatively with the physical, psychological and environmental WHOQOL-BREF domains. Older patients and those with higher levels of education influenced the improvement in patients' quality of life and functional capacity.

Conclusion: The improvement of adhesive capsulitis with treatment involves an improvement in quality of life and functional capacity. The greater functional capacity of the shoulder matches a better quality of life for patients. Age and education level are the variables that most influence improvement in quality of life and functional capacity.

Keywords: quality of life, adhesive capsulitis, shoulder pain, sickness impact profile, nerve block.

\section{INTRODUCTION}

Adopting a quality of life (QoL) assessment in clinical practice can assist therapy, allowing a more holistic approach to the individual that goes beyond the treatment of his disease. The difficulties in including this evaluation in clinical practice reside mainly in the health professionals' lack of information about its uses and applicability. ${ }^{1-3}$

Since this assessment reflects the perspective of the patient, and not that of scientists and health professionals, it is widely accepted as an indicator of health in medical interventions. ${ }^{3}$ Several tools may be used for this purpose, depending on the situation. ${ }^{1-4}$ The World Health
Organization Quality of Life (WHOQOL) questionnaire was initially developed as an expanded questionnaire, the WHOQOL-100, ${ }^{2}$ and later as the WHOQOL-BREF. ${ }^{5}$ The WHOQOL-BREF is an abbreviated version consisting of the 26 questions on the WHOQOL-100 with the best psychometric performance. $^{5}$

The Disabilities of the Arm, Shoulder, and Hand Questionnaire (DASH) is a self-administered regional questionnaire which assesses symptoms and the functional capacity (FC) of the affected upper limb. It was developed by the American Academy of Orthopedic Surgeons in collaboration with several other organizations. ${ }^{6}$ 
Adhesive capsulitis is a crippling, chronic and extremely painful disease that affects movement of the shoulder joint. The impairment of everyday activities such as bathing, getting dressed and driving interferes significantly with an individual's QoL.7 There are numerous treatments, including suprascapular nerve blocks (SSNB), ${ }^{7-9}$ which is an effective and safe procedure in the treatment of chronic diseases affecting the shoulder. The suprascapular nerve is the most important sensory nerve in the shoulder and is susceptible to blocking with local anesthetics. The large number of sympathetic fibers that this nerve supplies to the shoulder joint capsule was one of the reasons for choosing to treat adhesive capsulitis with SSNB. ${ }^{8}$

Studies of adhesive capsulitis patients most often involve symptoms such as pain and range of motion scales to analyze treatment results. ${ }^{9,10} \mathrm{QoL}$ and FC simultaneous assessment is not included in these studies, so this paper may contribute to patients' perception of their health status and treatment efficacy.

The general aim of this study was to evaluate patient-reported measures of QoL and FC in adhesive capsulitis before and after SSNB treatment. In addition, the influence of clinical and sociodemographic variables on both QoL and FC outcome and on the instruments' various domains, and the correlation between the respective instruments were analyzed.

\section{Method}

A prospective clinical study was performed with a cohort of adhesive capsulitis patients. The participants were patients selected during routine visits at a specialized clinic located in an orthopedic hospital.

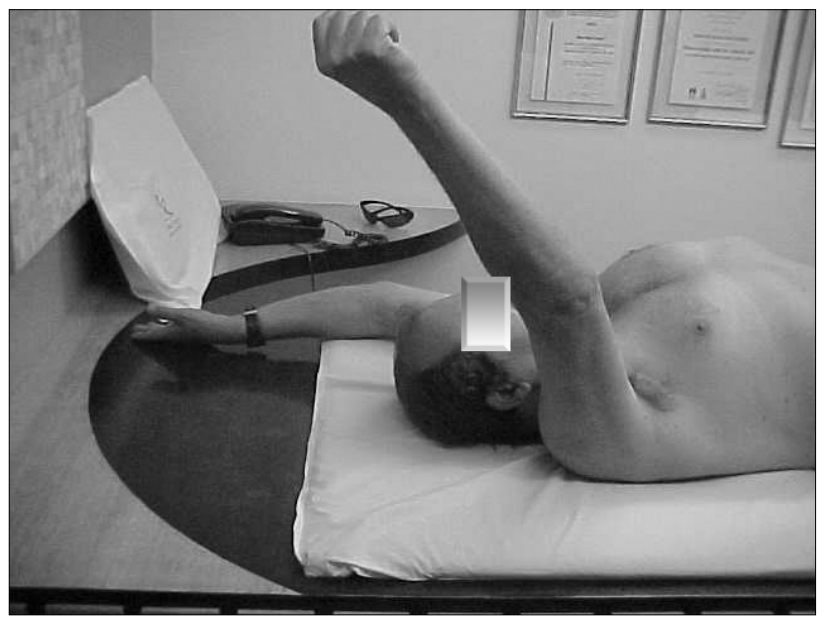

FIGURE 1 Anterior elevation limitation of the right shoulder.
Adhesive capsulitis was clinically diagnosed when there was constant pain lasting more than four weeks, with limitation on active and passive movements of the shoulder: anterior elevation to $130^{\circ}$ (Figure 1), external rotation to $50^{\circ}$ (Figure 2) and internal rotation to L5 (Figure 3). ${ }^{10}$

Inclusion criteria were a clinical diagnosis of adhesive capsulitis; existence of shoulder $\mathrm{X}$-ray exams with three views (true AP, axillary profile and scapular profile) and MRI scan in the previous 30 days; not under any concomitant adhesive capsulitis treatment, no subacromial space injection in the previous 15 days; and glycosylated hemoglobin less than or equal to $7 \%$ in case of associated diabetes. Exclusion criteria were concomitant pathologies such as complete lesion of the rotator cuff, instability, glenohumeral arthrosis and locked dislocation of the shoulder; stroke sequelae (hemiplegia or paresis); recent breast surgery; current chemotherapy or radiotherapy treatment; adhesive capsulitis with bilateral involvement and previous surgery on the affected shoulder.

Before each SSNB, the Constant score was calculated. The Constant test is a clinical method of functionally evaluating the shoulder. It combines an analysis of individual parameters with a 100 -point scoring system: the higher the score, the better the functional index. ${ }^{11}$ The cutoff point for interrupting blocks and making an overall assessment of patients' quality of life and FC using the WHOQOL-BREF and DASH was a constant score of 55 points or higher. The test was administered at the beginning of every clinical visit before any other procedure.

The SSNBs were performed on an outpatient basis following Dangoisse's technique ${ }^{12}$ without the aid of a peripheral nerve stimulator or imaging techniques: $8 \mathrm{~mL}$ of bupivacaine hydrochloride $0.5 \%$, with epinephrine

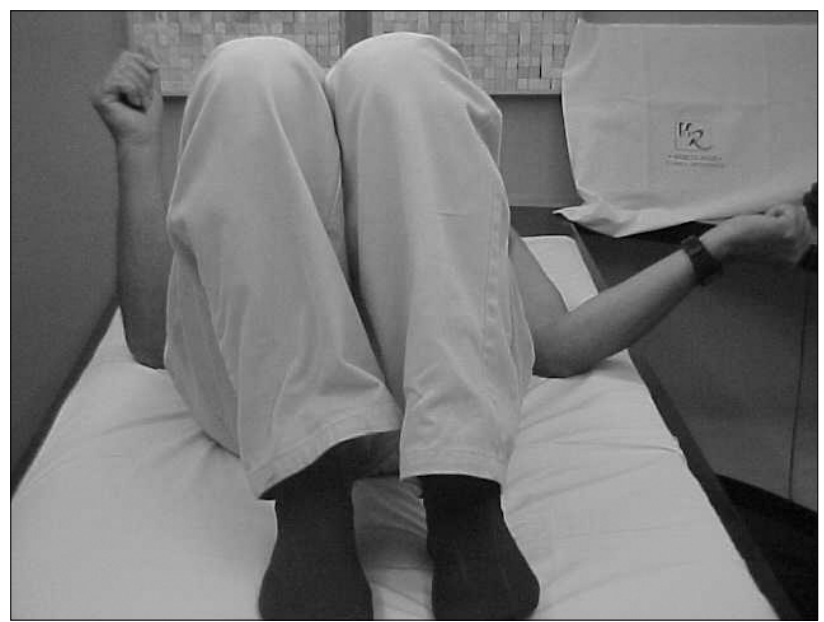

FIGURE 2 External rotation limitation of the right shoulder. 


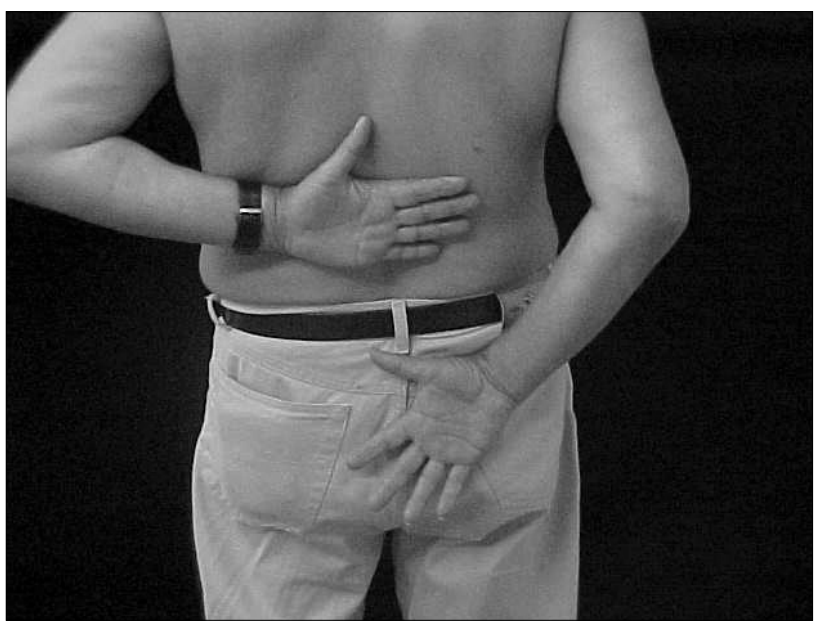

FIGURE 3 Internal rotation limitation of the right shoulder.

bitartrate 1:200,000 and without the association of corticosteroids, were used (Figure 4). The interval between blocks was seven days.

The sociodemographic variables were considered according to predetermined categories: age (complete years); gender (male/female); ethnic group (white/nonwhite); occupation (employed / unemployed); educational status (years of formal education); monthly income more or less than five minimum salaries; and marital status (married/ divorced/single/widowed).

Clinical variables were pain and active range of motion on Constant's scale ${ }^{11}$ where zero equals severe pain and 15 equals no pain. Anterior elevation and abduction were measured using a goniometer. The variables of dominance (right-handed/left-handed), sleep (unaffected/ affected) and side of the affected shoulder (right/left) were also studied. Zuckerman's classification ${ }^{13}$ was used to classify the disease and its clinical severity.

The outcome variable was QoL and FC. The evaluation took place before and after treatment with SSNB using the instruments WHOQOL-BREF (QoL), which the final score can range from zero to 100 (zero corresponding to the worst QoL and 100 to the best QoL), ${ }^{5}$ and DASH (FC), which score range from zero to 100 (the higher the score, the greater the level of functional disability). ${ }^{6}$ The questionnaires were self-administered.

This study was approved by Dr. Henrique Santillo Suleide - SES/GO research ethics committee on 6/23/2010 under number 0014.0.177.000-10.

\section{Statistical analysis}

Data were recorded on a spreadsheet (Microsoft Office Excel) and analyzed using the Statistical Package of Social

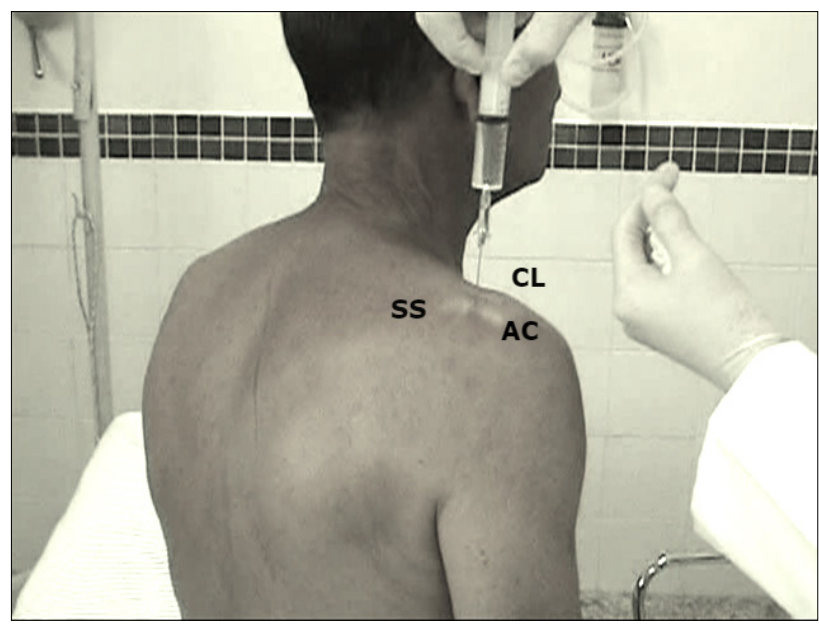

FIGURE 4 Suprascapular nerve block and anatomical landmarks. SS: spine of the scapula; AC: acromion; CL: clavicle.

Sciences (IBM - SPSS 20.0). Quantitative variables were reported as mean, median and standard deviation.

Chi-square test was used to study associations involving qualitative variables. After Shapiro-Wilk was conducted to test quantitative variables for normality, Mann-Whitney and Kruskal-Wallis or the parametric student t-test and ANOVA were applied.

The internal consistency of the instruments was analyzed by calculating Cronbach's alpha. The mean values found in each domain of the WHOQOL-BREF and DASH before and after treatment with SSNB were compared by paired t-test or the Wilcoxon test if the distribution was not parametric.

Analysis of correlation between the DASH variables and the WHOQOL domains used the Pearson or Spearman correlation depending on the type of distribution identified. The correlation analysis parameters were: 0.80 $<\mathrm{r}<1=$ very high; $0.60<\mathrm{r}<0.80=$ high; $0.40<\mathrm{r}<0.60=$ moderate; $0.20<\mathrm{r}<0.40=$ low; $0<\mathrm{r}<0.20=$ very low.

To determine the influence of the independent variables on the various WHOQOL domain and DASH scores both before and after treatment, a multiple linear regression analysis was performed, considering the WHOQOL domains and the DASH as the endpoints of each model. The independent variables that were used were those presenting significance values at $\mathrm{p}<0.20$ in the univariate analysis. For statistical tests, the level of significance was set at 0.05 .

\section{Results}

The total number of study participants was 43 . The mean age was 54.7 years (minimum 40 and maximum 75 ) and $23(53.5 \%)$ were female. The majority $(60.5 \%)$ had more 
than eight years of formal education. The secondary form of the disease occurred in $65.1 \%$ of cases, in $11.6 \%$ due to hypothyroidism and in $4.7 \%$ to diabetes mellitus. The left shoulder was affected in 25 (58.1\%) cases. The sociodemographic and clinical data of these adhesive capsulitis patients are shown in Table 1.

Cronbach's alpha values for WHOQOL-BREF and DASH, 0.91 and 0.95 , respectively, were exactly the same before and after treatment with SSNB. There was improvement in QoL in all domains of the WHOQOL-BREF ( $\mathrm{p}<0.001)$, least con- sistently in the social domain ( $\mathrm{p}=0.049)$. There was also a significant increase in the functional capacity of the affected shoulder when assessed using DASH (Table 2).

Before treatment with SSNB, DASH correlated only with the physical domain of the WHOQOL-BREF ( $\mathrm{r}=-0.583)$, but after this therapy there was significant correlation with the physical $(\mathrm{r}=-0.580)$, psychological $(\mathrm{r}=-0.521)$ and environmental $(\mathrm{r}=-0.370)$ domains. This means that the DASH value decreased as shoulder function improved and that QoL improved in the various domains.

\section{TABLE 1 Sociodemographic and clinical data of the study population.}

\begin{tabular}{|c|c|c|c|c|}
\hline Variables & & $\mathbf{n}$ & $\%$ & $\mathbf{p}^{*}$ \\
\hline \multirow[t]{3}{*}{ Age group } & $40 \mid---50$ & 14 & 32.6 & 0.977 \\
\hline & $50 \mid---60$ & 15 & 34.9 & \\
\hline & $60+$ & 14 & 32.6 & \\
\hline \multirow[t]{2}{*}{ Gender } & Female & 23 & 53.5 & 0.647 \\
\hline & Male & 20 & 46.5 & \\
\hline \multirow[t]{2}{*}{ Ethnic group } & White & 34 & 79.1 & 0.000 \\
\hline & Non-white & 09 & 20.9 & \\
\hline \multirow[t]{2}{*}{ Employment } & Yes & 20 & 46.5 & 0.647 \\
\hline & No & 23 & 53.5 & \\
\hline \multirow[t]{4}{*}{ Educational status } & Illiterate & 01 & 2.3 & 0.000 \\
\hline & Until 4 years of formal education & 08 & 18.6 & \\
\hline & 5 to 8 years of formal education & 08 & 18.6 & \\
\hline & More than 8 years of formal education & 26 & 60.5 & \\
\hline \multirow[t]{3}{*}{ Monthly income } & 1 to 5 minimum salaries & 27 & 62.8 & 0.000 \\
\hline & More than 5 minimum salaries & 12 & 27.9 & \\
\hline & No salary & 04 & 9.3 & \\
\hline \multirow[t]{4}{*}{ Marital status } & Single & 01 & 2.3 & 0.000 \\
\hline & Married & 32 & 74.4 & \\
\hline & Divorced & 07 & 16.3 & \\
\hline & Widower & 03 & 7.0 & \\
\hline \multirow[t]{2}{*}{ Side } & Right & 18 & 41.9 & 0.286 \\
\hline & Left & 25 & 58.1 & \\
\hline \multirow[t]{2}{*}{ Dominance } & Right-handed & 41 & 95.3 & 0.000 \\
\hline & Left-handed & 02 & 4.7 & \\
\hline \multirow[t]{2}{*}{ Classification } & Primary & 15 & 34.9 & 0.047 \\
\hline & Secondary & 28 & 65.1 & \\
\hline \multirow[t]{3}{*}{ Pain } & Mild & 02 & 4.7 & 0.000 \\
\hline & Moderate & 20 & 46.5 & \\
\hline & Severe & 21 & 48.8 & \\
\hline \multirow[t]{2}{*}{ Sleep } & Affected & 39 & 90.7 & 0.000 \\
\hline & Unaffected & 04 & 9.3 & \\
\hline \multirow[t]{3}{*}{ Severity } & Mild & 10 & 23.3 & 0.000 \\
\hline & Moderate & 27 & 62.8 & \\
\hline & Severe & 06 & 14 & \\
\hline
\end{tabular}


TABLE 2 Mean scores of WHOQOL-BREF domains, DASH and comparison between pre- and posttreatment of patients with adhesive capsulitis using suprascapular nerve block $(n=43)$.

\begin{tabular}{|c|c|c|c|c|c|}
\hline Domains & Mean & Median & SD & $\mathrm{Cl}$ & $\mathbf{p}$ \\
\hline Physical 1 & 45.34 & 46.42 & 19.75 & $39.27-51.43$ & $0.000 * *$ \\
\hline Physical 2 & 67.85 & 67.85 & 12.87 & 63.89-71.82 & \\
\hline Psychological 1 & 63.95 & 66.66 & 16.33 & $58.93-68.92$ & $0.000^{*}$ \\
\hline Psychological 2 & 73.54 & 79.16 & 15.77 & $68.69-78.40$ & \\
\hline Social 1 & 68.21 & 66.66 & 19.26 & $62.29-74.15$ & $0.049^{*}$ \\
\hline Social 2 & 73.83 & 75 & 19.29 & $67.90-79.77$ & \\
\hline Environment 1 & 60.24 & 62.50 & 15.62 & $55.44-65.06$ & $0.001 * *$ \\
\hline Environment 2 & 66.42 & 68.75 & 15.44 & $61.67-71.18$ & \\
\hline DASH 1 & 61.68 & 64.16 & 18.71 & $55.92-67.44$ & $0.000 * *$ \\
\hline DASH 2 & 42.11 & 38.33 & 18.30 & $36.48-47.74$ & \\
\hline
\end{tabular}

Before treatment, severe pain was the only independent variable that influenced the low values in the physical domain significantly, while younger subjects $(\mathrm{p}=0.03)$ and those with less education $(\mathrm{p}=0.02)$ influenced the low scores in the environmental domain. The influence of the female gender as an independent variable $(\mathrm{p}=0.004)$ was reflected in higher DASH scores.

Older patients with higher educational levels influenced posttreatment improvement of QoL in the physical, psychological and environmental domains of the WHOQOL-BREF and also influenced increased functional capacity of the shoulder assessed using DASH (Table 3).

\section{Discussion}

This study confirms that adhesive capsulitis is more predominant in females in the $5^{\text {th }}$ and $6^{\text {th }}$ generations, ${ }^{14}$ since it is a disease commonly associated with other systemic and non-systemic disorders ${ }^{15}$ found in $65.1 \%$ of cases, of which $11.6 \%$ were secondary to hypothyroidism. Bilateral disease was one of the study's exclusion criteria and, thus, it was not possible to compare our data with those in the literature, where the prevalence of bilateral disease is reported to be between 20 and $40 \%{ }^{10,14,15}$

The analysis of the results of disease treatment through scales assessing range of motion and strength only provides researchers with a single-faceted view of the patient's health conditions. ${ }^{9,16,17}$ However, the progress of research on QoL outcomes contributes to the perception of patients regarding their health and life by providing a validated subjective score of their symptoms, free from medical bias. ${ }^{1,3,4,6,14}$

The main objective of this study was to assess QoL and FC in adhesive capsulitis patients using two assessment instruments, WHOQOL-BREF and DASH. Gupta et al. stud- ied the impact of adhesive capsulitis in diabetic and elderly patients but used the Oxford Shoulder Score and Short Form-36 (SF-36) to do so. They concluded that adhesive capsulitis worsened the diabetics' quality of life. ${ }^{18}$

The course of this disease is prolonged, ${ }^{14,19}$ greatly impairing sleep and the patients' everyday activities and, therefore, their physical, psychological and social QoL as reflected in the various WHOQOL-BREF domains before SSNB treatment. Baums et al. used the SF-36 to examine the QoL of adhesive capsulitis patients before surgical release and found that the physical component was considerably affected..$^{20}$ The DASH score confirms major functional disability caused by adhesive capsulitis in the affected shoulder as cited in the literature. , $^{9,14}$

SSNB is one of the treatment options for adhesive capsulitis. ${ }^{8,16}$ It was used alone in the present research, on a weekly basis, with no simultaneous physiotherapy or any other additional method. Mitra et al. used a protocol of SSNB associated with three additional procedures for a synergistic therapeutic effect. Despite improvement in shoulder function, the authors were unable to say which fraction of the protocol was most effective. ${ }^{21}$ Shanahan et al. carried out SSNB without the aid of a nerve stimulator or imaging techniques, as in our study, but used $1 \mathrm{~mL}$ of $40 \mathrm{mg}$ methylprednisolone, associated with bupivacaine $0.5 \% .{ }^{22}$ Neither Mitra nor Shanahan assessed QoL as the outcome.

Importantly, after SSNB, mean QoL scores in all of the WHOQOL-BREF domains increased. This means that QoL that was low in all domains but lowest in the physical domain improved significantly after procedure. The domain that improved the least was the social domain, probably because adhesive capsulitis does not cause a 
TABLE 3 Results of multiple linear regression analysis of the WHOQOL-BREF domains and DASH after treatment among adhesive capsulitis patients.

\begin{tabular}{|c|c|c|c|c|c|}
\hline Explanatory variables & $\begin{array}{l}\text { PD } \\
\beta \text {-Standardized }\end{array}$ & $\begin{array}{l}\text { Ps D } \\
\beta \text {-Standardized }\end{array}$ & $\begin{array}{l}\text { SD } \\
\beta \text {-Standardized }\end{array}$ & $\begin{array}{l}\text { ED } \\
\beta \text {-Standardized }\end{array}$ & $\begin{array}{l}\text { DASH } \\
\beta \text {-Standardized }\end{array}$ \\
\hline Constant & 43.10 & 33.85 & 10.69 & 24.09 & 108.01 \\
\hline Pain & 0.16 & ------------ & ------------ & ------------ & ------------ \\
\hline Ethnic group & ------------ & ------------ & $0.43 * *$ & ------------ & ------------ \\
\hline Age group & $0.41^{*}$ & $0.38^{*}$ & 0.31 & $0.33 *$ & $-0.32^{*}$ \\
\hline Educational status & $0.31^{*}$ & $0.47^{* *}$ & $0.55^{* *}$ & $0.48^{* *}$ & $-0.34^{* *}$ \\
\hline Gender & 0.25 & ----------- & ----------- & ------------ & ------------ \\
\hline Marital status & ----------- & ------------ & ------------ & ------------ & ------------ \\
\hline Monthly income & -0.15 & -0.12 & ------------ & 0.00 & -0.01 \\
\hline Employment & ------------- & ------------ & -0.28 & 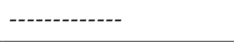 & -0.25 \\
\hline Side & - & 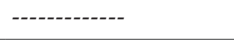 & 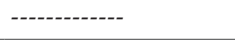 & 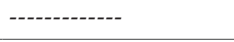 & 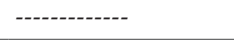 \\
\hline Dominance & 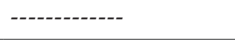 & 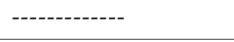 & 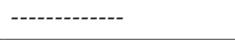 & 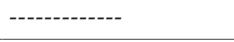 & 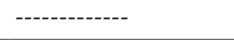 \\
\hline Classification & --------- & 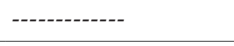 & ------o---- & ---------- & ---------- \\
\hline Sleep & ----------- & 0.10 & -0.02 & 0.16 & -0.11 \\
\hline Severity & -0.16 & - & - & --.-- & ---------- \\
\hline R2 & 0.40 & 0.29 & 0.51 & 0.31 & 0.42 \\
\hline Adjusted R2 & 0.25 & 0.21 & 0.41 & 0.23 & 0.33 \\
\hline $\mathrm{F}$ & 2.83 & 3.89 & 5.32 & 4.29 & 4.47 \\
\hline Significance F & 0.01 & 0.01 & 0.00 & 0.00 & 0.00 \\
\hline \multicolumn{6}{|c|}{ 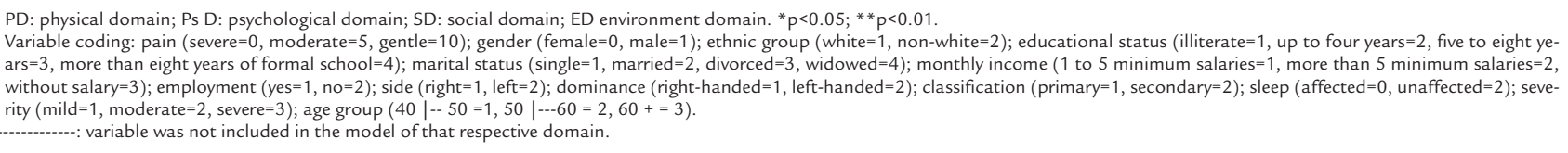 } \\
\hline
\end{tabular}

major impact on personal relationships with friends and relatives. On the other hand, the mean DASH score fell, indicating a decline in shoulder disability and consequent increase in the functioning of the affected shoulder.

A moderate correlation between DASH and the physical domain of the WHOQOL-BREF before therapy indicates that functional disability of the shoulder in adhesive capsulitis has similar effects on the physical aspect of QoL. However, an analysis of the correlation between the instruments after the blocks revealed a moderate negative correlation between the DASH and the physical and psychological domains, and a weak negative correlation between DASH and the environmental domain. This shows that the less severe the shoulder disability, the better the QoL.

The purpose of DASH is to assess the function of the affected region and the incapacity component of this function. The emphasis is on the physical aspect, with a particular focus on musculoskeletal disorders. Thus, the most expected correlation of DASH was with the physical domain of WHOQOL-BREF, which was in fact the highest $(r=-0.580)$. It may be that the small number of questions assessing patients' social function was insufficient to generate a correlation between DASH and the WHOQOL-BREF social domain.

Pain when adhesive capsulitis patients completed the initial questionnaire was the only independent variable that significantly influenced the physical domain of the WHOQOL-BREF. As $95.3 \%$ of cases had moderate to severe pain, this symptom could explain the low score in this domain before treatment (45.34). Our study also revealed that shoulder pain affected the patients' sleep, daily activities and ability to work. These items were part of the list of questions in this domain and the responses given suggested low QoL.

Multiple linear regression analysis after SSNB revealed that better educated patients positively influenced QoL in all domains of the WHOQOL-BREF. They also positively affected functional capacity as indicated by lower DASH scores. Except in the social domain, older patients positively influenced QoL on the WHOQOL-BREF and also influenced better functioning of the affected shoulder as measured by DASH.

The absence in the literature of studies comparing domain means before and after treatment and of analyses of 
the influence of the independent variables on the QoL of adhesive capsulitis patients made it impossible to compare the results of our study. Orthopedic diseases greatly impact patients' lives, affecting daily activities and consequently QoL. ${ }^{23-25}$ This study is therefore justified and this health indicator, QoL, needs to be evaluated more often, as already seen in other medical specialties. . $^{1,426-28}$

The simultaneous use of the WHOQOL-BREF and DASH represents an important contribution to the literature because there is a lack of knowledge regarding how these two instruments correlate in relation to this specific disease. Now it is possible to understand the QoL and FC in adhesive capsulitis as measures reported by the patients, before and after treatment. Pre-treatment QoL was low, particularly in the physical domain with impaired function of the shoulder. This explains why patients need medical care for both physical and social rehabilitation. After treatment, improved functional capacity of the affected shoulder led to an increase in QoL scores. ${ }^{6,23,29}$ Older and better educated patients weighed on the change in scores.

The strengths of our study lie in its prospective design, the use of assessment instruments for evaluating QoL and FC, well-defined exclusion criteria and the absence of similar research in the literature. Importantly, the clinical diagnosis of adhesive capsulitis was confirmed by imaging studies. Limitations include not having a control group treated with physical therapy or placebo for comparison, sampling that was not probabilistic, and a non-blinded outcome assessment.

In conclusion, SSNB improves the QoL and FC of patients with adhesive capsulitis. The greater functional capacity of the shoulder matches better QoL of patients. Age and education level are the variables that most influence improvement in QoL.

\section{Conflict of Interest}

The authors declare no conflict of interest.

\section{Resumo}

Medidas relatadas pelos pacientes sobre qualidade de vida e capacidade funcional em capsulite adesiva

Objetivo: Avaliar as medidas relatadas pelos pacientes sobre qualidade de vida e capacidade funcional em capsulite adesiva antes e após tratamento com bloqueios do nervo supraescapular; analisar a influência das variáveis clínicas e sociodemográficas em ambos os desfechos e a correlação entre os respectivos instrumentos.
Método: Estudo clínico prospectivo foi realizado em pacientes com capsulite adesiva. Os critérios de inclusão foram diagnóstico clínico de capsulite adesiva e realização de exames de imagem do ombro. Os instrumentos WHOQOL-BREF e DASH foram aplicados antes e após o tratamento. Utilizou-se o escore de Constant com ponto de corte em 55 para a interrupção do tratamento. As médias dos valores foram comparadas pelos testes t-pareado e Wilcoxon. $\mathrm{Na}$ análise de correlação foi utilizado o coeficiente de Pearson ou de Spearman. Foi realizada análise de regressão linear múltipla utilizando como preditoras as variáveis com $p<0,20$ na análise univariada e como desfechos os domínios do WHOQOL e o DASH. O nível de significância foi de $5 \%$.

Resultados: Foram avaliados 43 pacientes. A comparação entre as médias dos valores do WHOQOL-BREF e DASH antes e após os bloqueios apresentou um $p<0,05$. Houve correlação negativa entre o DASH e os domínios físico, psicológico e ambiental do WHOQOL-BREF. Os pacientes mais velhos e com maior grau de escolaridade influenciaram a melhora da qualidade de vida e capacidade funcional dos pacientes.

Conclusão: A melhora da capsulite adesiva com o tratamento implica melhora da qualidade de vida e capacidade funcional. Quanto maior a capacidade funcional do ombro, melhor a qualidade de vida dos pacientes. A faixa etária e o grau de escolaridade são as variáveis que mais influenciam a melhora da qualidade de vida e capacidade funcional.

Palavras-chave: qualidade de vida, capsulite adesiva, dor de ombro, perfil de impacto da doença, bloqueio nervoso.

\section{References}

1. Nesvold IL, Reinertsen KV, Fosså SD, Dahl AA. The relation between arm/ shoulder problems and quality of life in breast cancer survivors: a cross-sectional and longitudinal study. J Cancer Surviv. 2011; 5(1):62-72.

2. Fleck MPA, Leal OF, Louzada S, Xavier M, Chachamovich E, Vieira G, et al. [Development of the Portuguese version of the OMS evaluation instrument of quality of life]. Rev Bras Psiquiatr. 1999; 21(1):19-28.

3. Paananen M, Taimela S, Auvinen J, Tammelin T, Zitting P, Karppinen J. Impact of self-reported musculoskeletal pain on health-related quality of life among young adults. Pain Med. 2011; 12(1):9-17.

4. Silva RF, Conde DM, Freitas-Júnior R, Martinez EZ. Comparison of quality of life, satisfaction with surgery and shoulder-arm morbidity in breast cancer survivors submitted to breast-conserving therapy or mastectomy followed by immediate breast reconstruction. Clinics (Sao Paulo). 2010; 65(8):781-7.

5. Fleck MPA, Louzada S, Marta X, Chachamovich E, Vieira G, Santos L, et al. [Application of the Portuguese version of the abbreviated instrument of quality life WHOQOL-bref]. J Public Health. 2000; 34(2):178-83.

6. Aktekin LA, Eser F, Başkan BM, Sivas F, Malhan S, Öksüz E, et al. Disability of Arm Shoulder and Hand Questionnaire in rheumatoid arthritis patients: relationship with disease activity, HAQ, SF-36. Rheumatol Int. 2011; 31(6):823-6. 
7. Lorbach O, Anagnostakos K, Scherfb C, Seil R, Kohn D, Pape D. Nonoperative management of adhesive capsulitis of the shoulder: oral cortisone application versus intra-articular cortisone injections. J Shoulder Elbow Surg. 2010; 19(2):172-9.

8. Fernandes MR, Barbosa MA, Souza ALL, Ramos GC. Suprascapular nerve block: an important procedure in clinical practice. Braz J Anesth. 2012; 62(1):100-4.

9. De Carli A, Vadalà A, Perugia D, Frate L, Iorio C, Fabbri M, et al. Shoulder adhesive capsulitis: manipulation and arthroscopic arthrolysis or intra-articular steroid injections? Int Orthop. 2012; 36(1):101-6.

10. Zuckerman JD, Rokito A. Frozen shoulder: a consensus definition. J Shoulder Elbow Surg. 2011; 20(2):322-5

11. Constant CR, Murley AHG. A clinical method of functional assessment of the shoulder. Clin Orthop Relat Res. 1987; (214):160-4.

12. Dangoisse MJ, Wilson DJ, Glynn CJ. MRI and clinical study of an easy and safe technique of suprascapular nerve blockade. Acta Anaesthesiol Belg. 1994; 45(2):49-54

13. Zuckerman JD, Cuomo F, Rokito S. Definition and classification of frozen shoulder: a consensus approach. J Shoulder Elbow Surg. 1994; 3(1):S72.

14. Hand C, Clipsham K, Rees JL, Carr AJ. Long-term outcome of frozen shoulder. J Shoulder Elbow Surg. 2008; 17(2):231-6.

15. Manske RC, Prohaska D. Diagnosis and management of adhesive capsulitis. Curr Rev Musculoskelet Med. 2008; 1(3-4):180-9.

16. Favejee MM, Huisstede BMA, Koes BW. Frozen shoulder: the effectiveness of conservative and surgical interventions-systematic review. Br J Sports Med. 2011; 45(1):49-56.

17. Jewell DV, Riddle DL, Thacker LR. Interventions associated with an increased or decreased likelihood of pain reduction and improved function in patients with adhesive capsulitis: a retrospective cohort study. Phys Ther. 2009; 89(5):419-29.

18. Gupta S, Raja K, ManiKandan N. Impact of adhesive capsulitis on quality of life in elderly subjects with diabetes: a cross sectional study. Int J Diabetes Dev Ctries. 2008; 28(4):125-9.
19. Vastamäki H, Kettunen J, Vastamäki M. The natural history of idiopathic frozen shoulder: a 2- to 27-year follow up study. Clin Orthop Relat Res. 2012; 470(4):1133-43

20. Baums MH, Spahn G, Nozaki M, Steckel H, Schultz W, Klinger HM. Functional outcome and general health status in patients after arthroscopic release in adhesive capsulitis. Knee Surg Sports Traumatol Arthrosc. 2007; 15(5):638-44

21. Mitra R, Harris A, Umphrey C, Smuck M, Fredericson M. Adhesive capsulitis: a new $\mathrm{m}$ management protocol to improve passive range of motion. PM $\mathrm{R}$ 2009; 1(12):1064-8.

22. Shanahan EM, Shanahan KR, Hill CL, Ahern MJ, Smith MD. Safety and acceptability of suprascapular nerve block in rheumatology patients. Clin Rheumatol. 2012; 31(1):145-9.

23. Piitulainen K, Ylinen J, Kautiainen H, Häkkinen A. The relationship between functional disability and health-related quality of life in patients with a rotator cuff tear. Disabil Rehabil. 2012; 34(24):2071-5.

24. El-Daly I, Ibraheim H, Rajakulendran K, Culpan P, Bates P. Are patient-reported outcome measures in orthopaedics easily read by patients? Clin Orthop Relat Res. 2016; 474(1):246-55.

25. Laucis NC, Hays RD, Bhattacharyya T. Scoring the SF-36 in orthopaedics: a brief guide. J Bone Joint Surg Am. 2015; 97(19):1628-34.

26. Ogunlana MO, Adedokun B, Dairo MD, Odunaiya NA. Profile and predictor of health-related quality of life among hypertensive patients in south-western Nigeria. BMC Cardivasc Disord. 2009; 9:25.

27. Diouf M, Filleron T, Pointet AL, Dupont-Gossard AC, Malka D, Artru P, et al. Prognostic value of health-related quality of life in patients with metastatic pancreatic adenocarcinoma: a random forest methodology. Qual Life Res 2016; 25(7):1713-23.

28. Li MY, Yang YL, Liu L, Wang L. Effects of social support, hope and resilience on quality of life among Chinese bladder cancer patients: a cross-sectional study. Health Qual Life Outcomes. 2016; 14:73.

29. Fernandes MR, Barbosa MA, Souza ALL, Ramos GC. Suprascapular nerve block: an important procedure in clinical practice. Part II. Rev Bras Reumatol. 2012; 52(4):616-22. 